\title{
A speech-rate intelligibility threshold for speeded and time-compressed connected speech
}

\author{
HENRY J. de HAAN \\ U.S. Army Research Institute, Alexandria, Virginia 22333
}

\begin{abstract}
An automated threshold method has been developed for determining the maximum rate of speech understood by individual listeners. Two experiments were undertaken to determine whether the threshold was related to the comprehension of speech or to speech intelligibility. The first experiment compared thresholds of two types of rapid speech reportedly different in intelligibility: simple speeded speech and speech compressed by the sampling method. The second experiment sought to determine the relationship of the threshold to traditional comprehension measures. The results are discussed in terms of the intelligibility and comprehensibility of speech.
\end{abstract}

While the relationship of the intensity of speech to speech perception has been extensively investigated, the relationship of rapidity of speech to its perception has been less thoroughly explored. Recent technological advances have made it possible to reproduce speech at rates well beyond the limits of human capacity to understand it and have enabled investigators to explore the perception of rapid speech. Such speech is known as time-compressed, or simply compressed, speech. The simplest method of producing time-compressed speech is to increase the speed of a playback device above the speed at which the speech was originally recorded. This is sometimes referred to as the speed-changing method, and the speech so produced as speeded speech. This procedure increases not only the rate of speech but its pitch as well, since the frequency of the speech components varies directly with playback speed.

Another method of producing time-compressed speech is the so-called sampling method, and the speech produced by this method is usually referred to as compressed speech. The groundwork for this type of speech compression was laid by Miller and Licklider (1950), who found that interruptions of speech at 10 or more times per second did not interfere with intelligibility of a speech signal until relatively large amounts of the signal were discarded. Subsequently, Garvey (1953) explored the effects of cutting out short segments of a tape recording and physically rejoining the remaining parts. The resulting speech was time-compressed without the dis-

A preliminary report of this work was presented at the Annual Meeting of the Psychonomic Society, Denver, Colorado, November 6-8, 1975. Requests for reprints should be sent to Henry J. de Haan, U.S. Army Research Institute for the Behavioral and Social Sciences, Alexandria, Virginia 22333. The views expressed in this paper are those of the author and do not necessarily represent those of the Department of the Army. tortion in pitch. Fairbanks, Everitt, and Jaeger (1954) developed an electromechanical device to compress speech without the cumbersome manual manipulation used by Garvey, and more recently a number of electronic devices have been developed to compress speech by the sampling method. These devices sample the speech signal at very frequent intervals and discard a portion of each sample.

In investigations on the effects of the rapidity of speech, the methods for the evaluation of speech have been extensions or applications of methods used for the evaluation of conventional speech, namely, the measurement of comprehension and the measurement of intelligibility. The evaluation of compressed speech by these methods has been reviewed by Foulke and Sticht (1969). Comprehension measurement is applied to speech materials of some length, such as connected discourse or free-running speech, and is accomplished by asking questions concerning the content of the materials, usually in the form of objective multiple-choice questionnaires. A frequent finding is that comprehension declines as the rate of speech increases. Foulke (1971) and Foulke and Sticht (1969) have reported that when comprehension of compressed speech passages is measured, a rapid decline in comprehension is found above a speech rate of approximately 250 to 275 words per minute irrespective of the word rate of the original passage.

Another common method for evaluating speech, intelligibility testing, dervies from investigations of the ability of the telephone system to transmit speech. It has been used to investigate the intensive aspects of audition, specifically, the ability of a person to hear speech. In the articulation test, individuals are presented with brief messages at varying intensities, usually single words, but occasionally phrases or short sentences, and asked to repeat or correctly identify them. The threshold of intelligi- 
bility is defined as the intensity at which $50 \%$ of the materials so presented can be reproduced. In compressed speech research, similar procedures have been employed with single words compressed in time. For example, Garvey (1953) used the percentage of compressed words correctly identified as the index of intelligibility; Calearo and Lazzaroni (1957) determined the threshold intensity required for compressed word identification; and Foulke (Note 1) used reaction time for the identification of single compressed words as an index of intelligibility.

While the above methods of evaluating intelligibility are confined to brief materials, there have been several attempts to measure the intelligibility of connected, running speech (Chaiklin, 1959; Dahle, Hume, \& Haspiel, 1968; Falconer \& Davis, 1947; Haspiel \& Havens, 1966; Hawkins \& Stevens, 1950; LeZak, Siegenthaler, \& Davis, 1964; Speaks, Parker, Harris, \& Kuhl, 1972). In these studies, the listener was asked to adjust the intensity of the speech until he could just understand it, or some percentage of it. Many of the studies used the Békésy technique to determine speech intensity thresholds, and all of them were concerned with the intensity of the auditory signal required for understanding speech.

In spite of the preceding work, no threshold method for determining the maximum rate of speech understood by an individual based on variations in the rate of speech has been available. Consequently, a simple, direct, psychophysical threshold method was developed for this determination. The method is modeled after the automated threshold technique of Békésy (1947) for determination of the auditory threshold. The subject is required to respond to and control the changing rate of speech in order to bracket his threshold of understanding. Intensity is not varied. All stimuli are supraliminal in intensity and only the rapidity of speech is varied.

The method assumes that as speech becomes progressively more rapid a point is reached where the individual can no longer understand it. Accordingly, an attempt is made to determine this point by a threshold technique. The task set for the listener is essentially a perceptual one: $\mathrm{He}$ must perceive the point at which he fails to understand speech as its rapidity increases. Little published evidence exists that rate of speech perception is a variable which obeys the same psychophysical relationships as other perceptual variables, although Hutton (1955), using quite brief stimulus materials (ranging from 8.0 to $42.6 \mathrm{sec}$ in duration), found that perceived word rate was a logarithmic function of measured rate.

Both intelligibility and comprehension measurement contributed to the conceptualization of the threshold of understanding. The conclusion of Foulke and Sticht (1969) that a more rapid decline in comprehension occurs above 275 words per minute implied some sort of threshold of comprehension. Carver (1973a) has furnished additional support for a comprehersion threshold by deriving a so-called duration measure based on seconds per word instead of words per minute. Thresholds are well known in intelligibility testing. Garvey (1953) concluded that compressed speech was more intelligible than speeded speech by determining the intelligibility of single words by means of the articulation test. Minimum loudness thresholds for understanding connected speech, including speech-Békésy methods, have also been developed as described earlier.

Because a threshold is implied in both intelligibility and comprehension measurement, there was a question as to which of these constructs is measured by the present threshold. The purpose of the present work, therefore, was to determine whether the threshold was related to the comprehension of speech or to speech intelligibility. In order to accomplish this, two experiments were performed. The first experiment compared thresholds for two types of compressed speech previously reported to differ in intelligibility: simple speeded speech produced by the speed-changing method and compressed speech produced by the sampling method. At the same time, the effect of four different magnitudes of rate of change of speech speed (acceleration-deceleration) was studied. The second experiment presented several speech passages compressed by different amounts, and determined comprehension of the passages by means of questionnaires. The relationship of the threshold determinations to comprehension measures was studied.

\section{EXPERIMENT 1}

\section{Method}

Participants. Young military enlisted personnel with aptitude test scores of at least 110 (AFQT) and no known hearing defects participated in the research. Thirty-two individuals, including 25 males and 7 females, were assigned randomly to counterbalanced orders to be described later.

Stimulus materials. The stimulus materials were selected from "Talking Books," tape recordings prepared at the Library of Congress, Division for the Blind and Physically Handicapped. The selected recordings consisted of passages from a book of historical portraits, The Proud Tower by Barbara Tuchman (1966), read aloud by a female voice at the average rate of 126 words per minute (wpm) and recorded at a tape speed of $3.75 \mathrm{in.}$ $\sec (9.525 \mathrm{~cm} / \mathrm{sec})$. Eight passages were used for the threshold determinations.

Apparatus. A Crown (800 series) variable-speed tape recorder was used to reproduce speech. This recorder, together with a speed control device (Crown VSD-5), produced time-compressed speech by the speed-changing method (speeded speech). An AmBiChron (ABC) speech compressor (Koch, 1974) was used in conjunction with the above equipment to produce timecompressed speech by the sampling method (compressed speech). The AmBiChron compressor samples speech, writes the signal into a temporary memory, and reads the signal from memory at a rate that may be different from the writing rate. The rate of 
writing into memory is directly proportional to the tape transport speed (which refers to speed of the Crown tape recorder). The read-out rate is constant. In effect, comprehension discards brief segments of the speech signal, while expansion repeats brief segments. This device produced speech with normal pitch despite changing speeds.

Both the speed of the tape recorder and the pitch compensation of the AmBiChron were remotely controlled by a laboratoryfabricated device. Details of the instrumentation are available elsewhere (de Haan \& Schjelderup, Note 2). The device provided for an initial starting speed and constant rates of acceleration and deceleration which were selected by the adjustment of three potentiometers. Potentiometer settings had previously been calibrated in units of time required for the rapidity of speech to double.

The voltage applied to the tape recorder by the contro! circuits, which determined both the speed of the tape recorder and the pitch compensation of the AmBiChron, was displayed on a digital voltmeter and recorded in permanent form on a 6-in.-wide $(15.24 \mathrm{~cm})$ strip chart (Atomic Accessories, Model SR320) at $2 \mathrm{in} . / \mathrm{sec}(5.08 \mathrm{~cm} / \mathrm{sec})$. Another form of information about momentary speed of speech could be read from a digital frequency counter. All speech tapes contained one channel of a $1,000-\mathrm{Hz}$ tone recorded at $3.75 \mathrm{in} . / \mathrm{sec}(9.525 \mathrm{~cm} / \mathrm{sec})$. As the speed of the tape varied, the frequency changed proportionately and this information was displayed on the frequency counter.

Additional equipment included a small control box which enabled the individual participant to set the intensity and rate of speech (the latter was inactivated during the experiment proper), a pair of Grason-Stadler headphones (Telephonics, TDH 39), and a Grason-Stadler audiometer switch used to select either acceleration or deceleration. The rates of acceleration and deceleration were selected by potentiometer settings at $2.1,4.2,8.4$, and $16.8 \mathrm{wpm} / \mathrm{sec}$ for the four experimental rates of change. These values represented rates at which speech would change from the normal rate to double the normal rate during acceleration (or vice versa during deceleration) in $60,30,15$, and $7.5 \mathrm{sec}$ respectively.

Experimental design. The first independent variable was the type of time-compressed speech. There were two types, one of which was presented at each trial. In the first type, rate and pitch were interlocked and both were determined by the speed of the tape recorder. This is speeded, or type S, speech. In the second type, pitch was held constant while rate of speech was varied. This is compressed, or type $C$, speech.

The second independent variable was rate of change of speech speed, of which there were four levels. At each trial, speech was presented at one of four constant rates of change, 2.1, 4.2, 8.4, or $16.8 \mathrm{wpm} / \mathrm{sec}$. Whether it was accelerating or decelerating at any given moment was dependent on the subject's response.

The two types of compressed speech were combined with the four rates of change to yield eight experimental conditions under which thresholds were determined. All subjects were exposed to the eight conditions, but order of presentation of conditions differed. Speeded and compressed speech were presented on alternate trials, half the subjects receiving speeded speech first and half receiving compressed speech first. The order of rate of change conditions was partially counterbalanced, half the subjects receiving rate of change conditions in increasing order, the other half receiving rate of change conditions in decreasing order. This yielded four orders of presentation, to which subjects were randomly assigned, as follows:

$\begin{array}{llllllllllllllll}\text { (1) } & \mathrm{C} & 2.1 & \mathrm{~S} & 2.1 & \mathrm{C} & 4.2 & \mathrm{~S} & 4.2 & \mathrm{C} & 8.4 & \mathrm{~S} & 8.4 & \mathrm{C} 16.8 & \mathrm{~S} 16.8\end{array}$

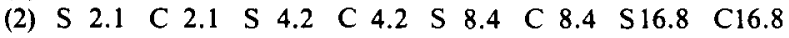

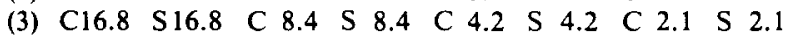

(4) $\begin{array}{llllllllllllll}\mathrm{S} 16.8 & \mathrm{C} 16.8 & \mathrm{~S} & 8.4 & \mathrm{C} & 8.4 & \mathrm{~S} & 4.2 & \mathrm{C} & 4.2 & \mathrm{~S} & 2.1 & \mathrm{C} & 2.1\end{array}$

Because of the partial counterbalancing shown above, the factor of trials was not formally analyzed.
Procedure. After receiving a brief explanation of the experiment, each participant was taken into the experimental chamber, fitted with headphones, and presented with a small control box with two knobs, one controlling volume and the other rate of speech. The tape recorder was turned on, and the participant was instructed to adjust the volume control to his own comfortable listening level.

Following this, the participant was familiarized with speeded and compressed speech. The experiment demonstrated the function of the rate knob by turning it through a range of approximately 0.5 to 3.0 times normal speed. The participant was then instructed to adjust the knob to set the speed at his or her own preference level. The same procedure was repeated with compressed speech. After completion of this short familiarization procedure, the control box was set to one side and the rate control was inactivated.

The participants were then individually introduced to the threshold task. A pushbutton switch (Grason-Stadler audiometer switch) was demonstrated while the task was explained to them. They were told that the speech would get faster automatically as long as the button was not pressed and that it would get slower as long as the button was pressed. They were instructed to press the button as soon as it became too fast to understand and to release the button as soon as they could understand it again, continuing this process until stopped by the experimenter. For most participants, no more instruction was required, although a few required a repetition and emphasis of some part of the instructions. Each participant's threshold was determined eight times, one 3-min threshold being determined under each of the eight conditions previously described.

\section{Results}

Raw data were recorded in analog form. The numerical values of the upper and lower points of the sawtooth records were transcribed and multiplied by 5.04 to transform voltage into words per minute. All further analysis was done on this transformed data. The mean of each record represented the absolute threshold, while the difference between means of the upper and lower points represented the difference limen.

Figure 1 presents the threshold data for both speeded and compressed speech at each rate of acceleration-deceleration. The difference between the thresholds for speeded and compressed speech is clearly evident; the mean value for compressed speech was $265.96 \mathrm{wpm}$ while that for speeded speech was $217.75 \mathrm{wpm}$. An analysis of variance revealed a significant effect of type of speech compression, $F(1,28)=191.94, p<.01$. Although the curves in Figure 1 show only a slight rate of change, this effect was statistically significant, $F(3,84)=4.08, p<.01$. However, the interaction of rate with order of presentation was also significant, $F(3,84)=6.43$, $p<.01$. Comparison of individual means by Tukey's HSD test revealed that, while means for the various rates in the decreasing order group did not differ, the means for the two fastest rates in the increasing order group were higher than that for the slowest rate, $\mathrm{q}(2,112)=3.02$ and 3.15 , respectively, $\mathrm{p}<.05$. This indicates that the slight rise in the curves in Figure 1 can be completely accounted for by the increasing order of presentation. 


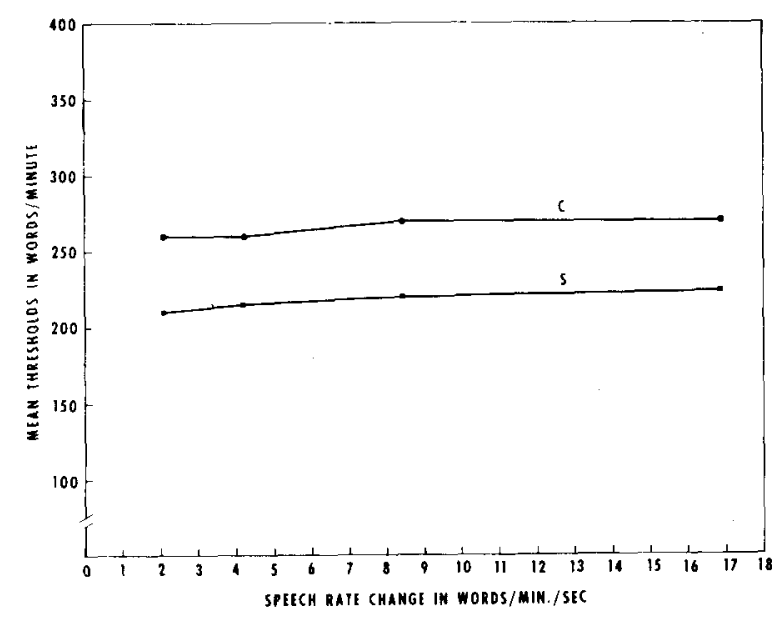

Figure 1. Mean thresholds of speeded and compressed speech at four rates of acceleration-deceleration.

The mean difference limens, which correspond to the amplitude of the rate-swings as the subject tracks his threshold, are shown in Figure 2 at each rate of acceleration-deceleration. The effect of type of speech compression is again evident, $F(1,28)=$ $74.85, p<.01$. In contrast to the rather small effect of rate of change on the absolute threshold, the analysis revealed a pronounced effect of rate of change on the difference limen, $F(3,84)=370.16$, $\mathrm{p}<.01$. Figure 2 indicates that the size of the difference limen is roughly proportional to the rate of change. Figure 2 also shows a greater increase in the difference limen for compressed vs. speeded speech, and the analysis indicated an interaction of type of speech compression with rate of change, $F(3,84)=$ 43.92, $\mathrm{p}<.01$. Further analysis by means of Tukey's HSD revealed that, while the difference between the pair of means at the slowest rate was not significant, differences between the pair of means at each of the three higher rates were significant $\mathrm{q}(2,112)=4.17$, 9.87 , and 19.00 , respectively, $p<.01$. Increasing order of presentation also yielded higher difference limens than did decreasing order of presentation, $\mathrm{F}(1,28)=11.34, \mathrm{p}<.01$, and there was an interaction between rate and order of presentation, $\mathrm{F}(3,84)=3.20, \mathrm{p}<.05$.

\section{EXPERIMENT 2}

\section{Method}

Participants. The same individuals who had participated in Experiment 1 participated in Experiment 2.

Stimulus materials. Stimulus materials came from the same source as those in Experiment 1, but consisted of different passages, seven in all, from The Proud Tower. Comprehension tests on the content of these passages had been prepared and standardized for use in another study (Lambert, Shields, Gade, \& Dressel, Note 3 ). These tests consisted of 10 multiple choice questions on each of the passages. Thirty individuals from the larger standardization group of Army communication trainees had been exposed to all seven passages. These 30 individuals comprise the standardized control group for the present study. All passages had been presented to the control group at normal speed (136 wpm).

For the experimental group, a tape was prepared of the seven passages compressed to the following rates, where $x$ indicates "times the normal speech rate": $1.50 \times(203 \mathrm{wpm}), 1.75 \times$ $(249 \mathrm{wpm}), 2.00 \times(284 \mathrm{wpm}), 2.25 \times(306 \mathrm{wpm}), 2.50 \times$ (330 wpm), $2.75 \times(360 \mathrm{wpm})$, and $3.00 \times(408 \mathrm{wpm})$.

Apparatus. The same apparatus was used in Experiment 1 and Experiment 2. The compressed speech tape was prepared with the AmBiChron speech compressor, and reproduced by means of the Crown recorder at $3.75 \mathrm{in} . / \mathrm{sec}(9.525 \mathrm{~cm} / \mathrm{sec})$.

Procedure. Participants in Experiment 1 were given a 5- or 10 -min rest period before being brought back to the laboratory to participate in Experiment 2. At this time, the purpose of the comprehension experiment was explained to them. They were told that seven passages would be presented to them, each of which would be faster than the preceding one, the final passages being extremely rapid. They were also told that a multiple choice test would be administered following each passage in which they would be expected to answer all questions. Passages were then presented one at a time, each followed by 10 multiple choice questions. Test 1 followed the passage presented at $1.5 \times$, Test 2 the passage at $1.75 \times$, and so on, through Test 7 following the passage at $3.0 \times$.

\section{Results}

Table 1 shows the mean comprehension test scores for both experimental and control groups for each of the seven passages, together with the compression ratio at which each passage was presented. The differences between the experimental and control groups are also shown. These differences were found by subtracting control group means from their respective experimental group means. Consequently, a positive difference indicates that the experimental group was superior to that of the control group, while a negative difference indicates that the experimental group was inferior to the control group.

Figure 3 presents the group means of the experimental and control groups, as well as the difference between the respective means without regard to the sign of the difference. It may be observed that comprehension of the experimental group decreased as the compression ratio increased, but that mean comprehension scores of certain of the tests in the control group were lower than that of others, especially Test 6 . In general, comprehension scores of the experimental group were reduced relative to the control group as the compression ratio increased.

The comprehension test scores were subjected to a repeated measures analysis of variance. Experimental and control group means were significantly different, $F(1,60)=7.90, p<.01$. Tests were also a significant source of variation, $F(6,360)=12.51, p<.01$, as was the interaction of tests with conditions, $F(6,360)$ $=4.70, p<.01$. Analysis of variance for the simple main effects of the experimental variable yielded 


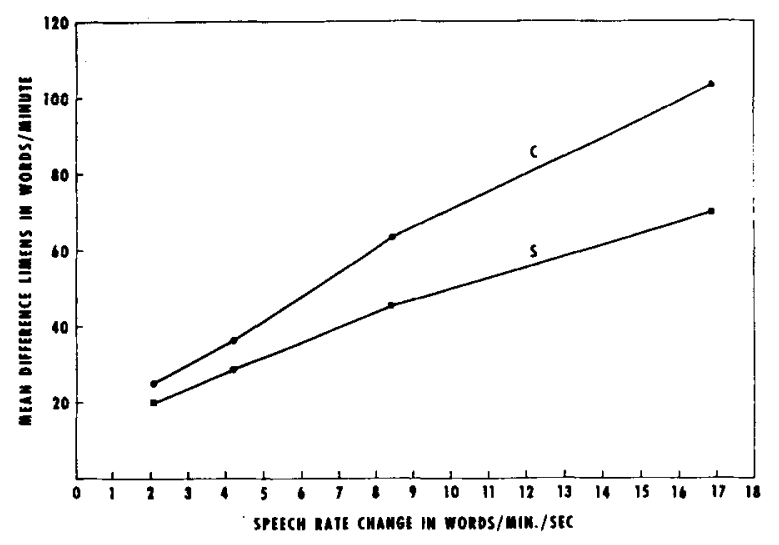

Figure 2. Mean difference limens of speeded and compressed speech at four rates of acceleration-deceleration.

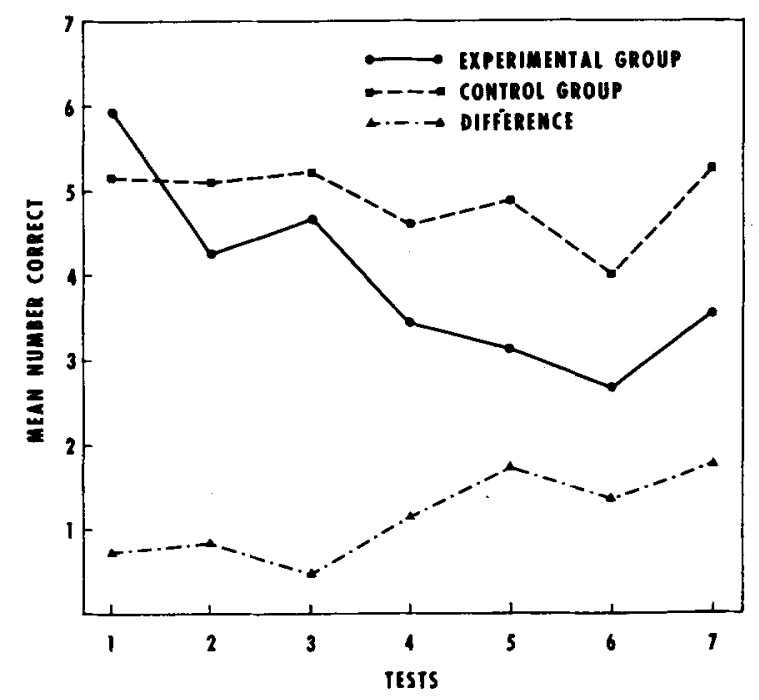

Figure 3. Mean comprehension test scores of experimental and control groups. the following values of $\mathrm{F}$ for Tests 1 and through 7 , respectively: $2.36,2.87,1.04,5.37,12.07,7.19$, and 11.92. The values for Tests 5,6 , and 7 were significant at the .01 level, $F(1,60), p<.01$, while the value for Test 4 was significant at the .05 level, $F(1,60)$, $\mathrm{p}<.05$. This indicates that the experimental group exhibited a significantly lower degree of comprehension than the control group when the word rate reached approximately $306 \mathrm{wpm}$.

Of primary interest was the correlation of the comprehension test scores with the thresholds determined in Experiment 1. Pearson product-moment correlation coefficients were obtained between each of the eight threshold conditions and the seven comprehension tests. The two highest correlations, .55 and .48 , respectively, were between each of the types of speech at the slowest rate of change $(2.1 \mathrm{wpm} / \mathrm{sec})$ and the first comprehension test $(1.5 \times$ normal speed). In general, the other correlations were quite low. This indicates that there is little relationship between thresholds and comprehension test scores in the present experiment.

Reliabilities of the comprehension tests for the control group were determined by Kuder-Richardson Formula 20 and yielded the following reliability coefficients for Tests 1 through 7, respectively: .56, $.55, .66, .62, .76, .46$, and .44 . Undoubtedly the relationship between thresholds and comprehension scores was somewhat attenuated by these moderate reliabilities.

\section{DISCUSSION}

This study was undertaken to determine the relationship of the threshold to traditional psychology constructs such as speech intelligibility and comprehension. The results of Experiment 1 support the hypothesis that the threshold is a measure of intelligibility for connected speech. Garvey (1953) compared the intelligibility of single words

Table 1

Mean Comprehension Test Scores

\begin{tabular}{|c|c|c|c|c|c|c|c|c|}
\hline & \multicolumn{3}{|c|}{ Control Group } & \multicolumn{4}{|c|}{ Experimental Group } & \multirow[b]{2}{*}{$\begin{array}{c}\text { Mean } \\
\text { Difference }\end{array}$} \\
\hline & $\begin{array}{c}\text { Compres- } \\
\text { sion } \\
\text { Ratio }\end{array}$ & $\begin{array}{c}\text { Word } \\
\text { Rate } \\
\text { (WPM) }\end{array}$ & $\begin{array}{c}\text { Mean } \\
\text { Test } \\
\text { Score }\end{array}$ & $\begin{array}{c}\text { Compres- } \\
\text { sion } \\
\text { Ratio }\end{array}$ & $\begin{array}{l}\text { Discard } \\
\text { Interval } \\
\text { (msec) }\end{array}$ & $\begin{array}{l}\text { Retained } \\
\text { Interval } \\
\text { (msec) }\end{array}$ & $\begin{array}{c}\text { Mean } \\
\text { Test } \\
\text { Score }\end{array}$ & \\
\hline 1 & 1.00 & 135 & 5.17 & 1.50 & 13.3 & 26.7 & 5.94 & +.77 \\
\hline 2 & 1.00 & 142 & 5.10 & 1.75 & 11.4 & 15.2 & 4.25 & -.85 \\
\hline 3 & 1.00 & 142 & 5.20 & 2.00 & 10.0 & 10.0 & 4.69 & -.51 \\
\hline 4 & 1.00 & 136 & 4.60 & 2.25 & 8.9 & 7.1 & 3.44 & $-1.16^{*}$ \\
\hline 5 & 1.00 & 132 & 4.90 & 2.50 & 8.0 & 5.3 & 3.16 & $-1.74 * *$ \\
\hline 6 & 1.00 & 131 & 4.03 & 2.75 & 7.3 & 4.2 & 2.69 & $-1.34 * *$ \\
\hline 7 & 1.00 & 136 & 5.27 & 3.00 & 6.7 & 3.3 & 3.53 & $-1.74 * *$ \\
\hline
\end{tabular}


compressed by the sampling method with those compressed by the speed-changing method and found a higher percentage of intelligibility for those compressed by the sampling method. This finding is in agreement with the results of the present experiment on connected speech, which found a higher threshold for compressed than for speeded speech. The agreement is, in fact, rather close. In the present experiment, the thresholds for compressed speech and speeded speech are approximately 2.1 and 1.7 times the normal speech rate, respectively. Assuming that the two types of speech are equivalent in intelligibility at these rates, a comparison may be made with Garvey's data for intelligibility of single words. Garvey found that approximately $95 \%$ of the compressed words were intelligible at 2.0 times the normal speech rate, while approximately $90 \%$ of the speeded words were intelligible at 1.7 times the normal speech rate.

The results of this experiment also indicated that, not only was compressed speech more intelligible than speeded speech, but changes in the intelligibility of compressed speech were more difficult to detect. This may be due to cues for pitch interacting with intelligibility in the case of speeded speech in such a way that the detection of change is made easier.

The results of Experiment 2 do not support the hypothesis that the threshold is a measure of comprehension. Correlations between threshold values and traditional comprehension test scores were generally low. In view of the lack of relationship between the thresholds and traditional comprehension measures, one fact still demands explanation: The mean value of the compressed speech threshold, approximately $265 \mathrm{wpm}$, is in close agreement with the point at which Foulke and Sticht $(1969)$ have claimed that comprehension falls off rapidly, namely 250 to $275 \mathrm{wpm}$. Although the work of Carver (1973a) also supports the notion of a threshold in comprehension measurement, his duration measure (seconds per word) placed the threshold at the equivalent of $150 \mathrm{wpm}$, which does little to explain the similarity of the present value to that of Foulke and Sticht.

Prior to the collection and analysis of the data, it was thought that it might be possible to measure comprehension by the threshold method. Nevertheless, during the collection of the data, the neutral term "understand" was used in the instructions rather than references to "comprehension" or "intelligibility," since it seemed to communicate the task to the participants. In retrospect, it should be said that the conditions of the experiment, particularly rates of change which involved potential doubling of the speech rate in 7.5 to $60 \mathrm{sec}$, operationally defined the concept and perhaps precluded any other interpretation, in spite of differing connotations of "understand" which individuals may have brought to the laboratory.

Deese (1969) has suggested that understanding is a valid psychological construct. Schwartz, Sparkman, and Deese (1970) found that subjective judgments of the comprehensibility of isolated sentences could be validated against structural complexity of the sentences or against readability indices. Moreover, the work by Carver (1973a, 1973b), was based on the percentage of thoughts in a passage which a listener judged that he understood. Deese and his students believe that during rapid reading, intermittent interpretation takes place rather than the full process necessary for comprehension. Although a person may not place an interpretation on everything he reads or hears, he has a kind of monitoring device which informs him that he has the ability to interpret it. Deese has called this inward sign the "feeling of understanding" which signals comprehensibility rather than comprehension per se. From all of the foregoing, it must be concluded that comprehensibility is an alternative construct that should be considered.

Which of these three alternatives is the threshold measuring? There is evidence for intelligibility and against comprehension. But what about comprehensibility? The notion is intuitively appealing, the term "understand" was used in the instructions to subjects, and comprehensibility would appear to be a construct in search of a measurement method. Nevertheless, without independent evidence that the threshold is a measure of comprehensibility, it would seem that the most defensible interpretation of the threshold at present is that it is a measure of intelligibility. Accordingly, it may be referred to as the "threshold of intelligibility of rapid connected speech." On the other hand, the term "speechperception rapidity threshold" might be preferable, since it is descriptive, theoretically neutral, and serves to distinguish the threshold from those based on loudness.

Beyond the theoretical considerations concerning the psychological constructs underlying the threshold method, research should be directed toward the variables to which the method may be sensitive. It has already been demonstrated that the method is sensitive to individual differences: There is a wide range of variation in threshold values among subjects. If the threshold method is a valid way of measuring the understanding of rapid speech, the implication of this finding is that group presentation of rapid auditory information is inappropriate. Since the threshold varies from one person to another, provision should be made for allowing each individual to listen at his own rate.

Research should also be directed toward investigating how various characteristics of speech 
materials affect the threshold. One would expect that the threshold might well vary with the difficulty of speech material, or even with syntactic and semantic variables underlying difficulty. It might be possible to use the threshold to determine the listenability of auditory material just as readability of printed material is determined.

The threshold method may also be sensitive to the quality of speech produced by speech compression devices and speech synthesizers. Should this prove to be the case, one would expect that the better the quality of speech, the higher would be the threshold values. Thus, the method might be used to evaluate and compare these devices.

It is assumed that the threshold basically reflects some temporal limit of information processing. It is not presently known whether this limit is peculiar to the auditory modality or whether more central processes are involved. Should the latter prove to be true, research on compressed speech may considerably elevate the status of listening as compared with reading as a way of gaining information.

\section{REFERENCES NOTES}

1. Foulke, E. The comprehension of rapid speech by the blind: Part III. Final progress report. Cooperative Research Project No. 2430. Washington, D.C: USDHEW, Office of Education, 1969.

2. de Haan, H. J., \& Schjelderup, J. R. Threshold of intelligibility/comprehensibility of rapid connected speech: Method and instrumentation. In preparation.

3. Lambert, J. V., Shields, J. L., Gade, P. A., \& Dressel, J. D. Comprehension of time-compressed speech as a function of training. Technical paper, U.S. Army Research Institute, in press.

\section{REFERENCES}

BÉKÉSY, G. VON. A new audiometer. Acta Otolaryngologica, 1947, 35, 411-422.

CARver, R. P. Effect of increasing the rate of speech presentation upon comprehension. Journal of Educational Psychology, 1973, 65. 118-126. (a)

CARver, R. P. Understanding, information processing, and learning from prose materials. Journal of Educational Psychology, 1973, 64, 76-84. (b)

Calearo, C., \& Lazzaroni, A. Speech intelligibility in relation to the speed of the message. Laryngoscope, 1957, 67, 410-419. .
Chaiklin, J. B. The relation among three selected auditory speech thresholds. Journal of Speech \& Hearing Research, 1959, 2. 237-243.

Dahle, A. J., Hume, W. C., \& Haspiel. G. S. Comparison of speech-Békésy tracings with selected clinical auditory measures. Joumal of A uditory Research, 1968, 8, 125-128.

DeEse, J. Behavior and fact. American Psychologist, 1969, 24. 515-522.

Fairbanks, G., EveritT, W. L., \& JAEger, R. P. Method for time or frequency compression-expansion of speech. Transactions of the Institute of Radio Engineers. Professional Group on Audio AV2(1), 7-12, 1954. (Excerpts in Duker, S. Time compressed speech: An anthology and bibliography. Metuchen, N.J: Scarecrow Press, 1974.)

Falconer, G.. \& Davis, H. The intelligibility of connected discourse as a test for the threshold of speech. Laryngoscope, 1947, 57. 581-595.

FoULKE, E. The perception of time compressed speech. In D. L. Horton and J. J. Jenkins (Eds.), Perception of language. Columbus, Ohio: Merrill, 1971.

Foulke, E., \& Sticht. T. G. A review of research on time compressed speech. Psychological Bulletin, 1969, 72, 50-62.

GaRveY, W. D. The intelligibility of speeded speech. Joumal of Experimental Psychology, 1953, 54, 102-108.

Haspiel, G.. \& Havens, R. Comparison of speech Békésy with pure tone Békésy thresholds. Journal of Auditory Research, 1966. 6. 235-237.

Hawkins. J. E., \& Stevens, S. S. The masking of pure tones and of speech by white noise. Journal of the Acoustical Society of America, 1950, 22, 6-13.

Hutton, C. L. Psychophysical study of speech rate. Dissertation Abstracts, 1955, 15. 168. (Excerpts in Duker. S., Time compressed speech: An anthology and bibliography. Metuchen, N.J: Scarecrow Press, 1974.)

Koch, R. The AmBiChron. In S. Duker (Ed.), Time compressed speech: An anthology and bibliography. Metuchen, N.J: Scarecrow Press, 1974.

LeZak, R. J., Siegenthaler, B. R., \& Davis, A. J. Békésy-type audiometry for speech reception threshold. Journal of Auditory Research, 1964, 4, 181-190.

MILlER, G. A., \& LICKLIDER, J. C. The intelligibility of interrupted speech. Journal of the Acoustical Society of America. 1950, 22, 167-173.

Schwartz, D., Sparkman, J. P., \& Deese, J. The process of understanding and judgments of comprehensibility. Journal of Verbal Learning \& Verbal Behavior, 1970, 9, 87-93.

Speaks, C., Parker. B., Harris, C., \& Kuhl, P. Intelligibility of connected discourse. Journal of Speech \& Hearing Research, $1972,15,590-602$.

Tuchman, B. The proud tower. New York: Macmillan, 1966.

(Received for publication February 28, 1977; revision accepted June $28,1977$. ) 